\title{
Cross-linguistic influence, cross-linguistic priming and the nature of shared syntactic structures
}

Article

Accepted Version

Serratrice, L. (2016) Cross-linguistic influence, cross-linguistic priming and the nature of shared syntactic structures.

Linguistic Approaches to Bilingualism, 6 (6). pp. 822-827. ISSN 1879-9264 doi: https://doi.org/10.1075/lab.6.6.15ser Available at https://centaur.reading.ac.uk/71060/

It is advisable to refer to the publisher's version if you intend to cite from the work. See Guidance on citing.

Published version at: http://dx.doi.org/10.1075/lab.6.6.15ser

To link to this article DOI: http://dx.doi.org/10.1075/lab.6.6.15ser

Publisher: John Benjamins

All outputs in CentAUR are protected by Intellectual Property Rights law, including copyright law. Copyright and IPR is retained by the creators or other copyright holders. Terms and conditions for use of this material are defined in the End User Agreement.

www.reading.ac.uk/centaur

\section{CentAUR}


Central Archive at the University of Reading

Reading's research outputs online 


\section{Cross-linguistic influence, cross-linguistic priming and the nature of shared syntactic structures}

\section{Ludovica Serratrice \\ University of Reading}

Lillo-Martin, Müller de Quadros and Chen Pichler (2016) (henceforth LMC) propose a model of language representation in bimodal bilinguals they call the Language Synthesis model (henceforth LSM). The aim of the model is to provide a unified treatment of a range of bilingual grammatical phenomena, i.e., crosslinguistic influence/transfer, code-switching and code-blending. Dealing with bilingual data, by definition, requires a representational model of grammar that can accommodate both languages. Some, like Amaral and Roeper (2014) have gone down the route of Multiple Grammars; they proposed a model of syntactic representation where multiple sub-grammars coexist in the mind of the bilingual speaker and are selected as required. LMC have gone the opposite route; they advocate a model where there are essentially no differences between bilingual and monolingual speakers, or between the spoken and the manual modality. The authors capitalize on a modified version of MacSwan's (2000; 2005; 2014) approach to code-switching that makes no special stipulations to account for bilingual language data. In MacSwan's model all surface constraints are the results of grammatical requirements that are part of the universally available computational system. In addition, LMC follow den Dikken's (2011) approach to Halle and Marantz' (1993) Distributional Morphology framework that can account for both code-switching phenomena - when Vocabulary Items from one 
or the other language are inserted late in the derivation - and instances of crosslinguistic influence - when Lexical Items (i.e. roots and morphemes) from one or the other language are the early input to the syntactic derivation.

Although LMC specifically state that the LSM is not a production model, it addresses the issue of syntactic structure formulation and hence it is relevant for sentence production. In their paper they examine different sets of data that speak to a range of bilingual production phenomena: cross-linguistic influence, code-switching and code-blending.

Here I will focus on cross-linguistic influence and discuss it as the outcome of syntactic priming across languages. I believe that this is where the LSM has a role to play in defining the nature of what is shared, when and how.

Over the last 40 years the study of morpho-syntactic development in bilingual children has moved from a one-system account with no initial syntactic differentiation (Volterra \& Taeschner, 1978), to a two-system approach where bilinguals develop language-specific syntactic representations from the start (De Houwer, 1990; Genesee, 1989; Meisel, 1989), to a model in which languages are indeed differentiated but where pockets of systematic cross-linguistic influence do exist (Hulk \& Müller, 2000; Paradis \& Navarro, 2003; Serratrice, Sorace \& Paoli, 2004). Lately, some researchers have started to entertain the idea that a more parsimonious and psycholinguistically viable account of the bilingual language architecture must include shared syntactic representations (Hartsuiker et al., 2004; Hartsuiker, Beerts, Loncke, Desmet, \& Bernolet, 2016). This line of inquiry has mostly investigated the role of syntax in adult bilinguals in the framework of syntactic priming (Bernolet, Hartsuiker, \& Pickering, 2007; Desmet \& Declercq, 2006; Kantola \& van Gompel, 2011; Loebell \& Bock, 2003). 
The rationale behind priming is that the processing of a syntactic structure either in comprehension or in production - facilitates its subsequent use (Bock, 1986). The priming literature has appealed to the existence of shared syntactic representations to account for cross-linguistic priming in adult and child bilinguals (Hartsuiker, Pickering, \& Veltkamp, 2004; Vasilyeva et al. 2010). While there have been explicit proposals regarding the mechanisms of bilingual sentence production (Hartsuiker \& Pickering, 2008), the architecture of the bilingual grammar that would allow such shared structures has been somewhat underspecified. Two main mechanisms have been proposed to account for priming effects. According to Chang, Dell, and Bock (2006) the processing of the mapping between semantics and syntax in a given structure (i.e. transfer of possession using a Double Object construction as in Laura threw Penny a ball) increases the likelihood that the same message will be expressed by that same structure over time, eventually leading to a form of implicit learning. In the socalled lexicalist approach, Pickering and Branigan (1998) proposed that priming arises from the increased activation of construction nodes associated with the lemma nodes of the verb in the construction so that processing a sentence like Laura threw Penny a ball will increase both the activation level of the Double Object construction and of the verb throw.

Syntactic priming effects are well established in the adult literature and are now well attested in the developmental literature, too (Branigan \& McLean, 2016; Hervé, Serratrice, \& Corley, 2015; Hsin, Legendre, \& Omaki, 2013; Vasilyeva, Waterfall, Gamez, Gomez, Bowers, \& Shimpi, 2010; Wolleb, 2015). The finding that syntactic priming can work not only within languages in monolingual speakers, but across languages too in bilingual individuals - both 
children and adults - has implications for our conceptualization of how knowledge of grammar is stored and accessed. If hearing a passive in Spanish successfully leads to the priming of a passive in English, at some level, the representation of the passive must be shared across the two languages. Existing evidence so far has shown that cross-linguistic priming is most likely to occur when structures are aligned with respect to function and word order. More intriguingly, there is some emerging evidence from the developmental literature that cross-linguistic priming can result in an ungrammatical (Hsin et al., 2013) or discourse-pragmatically sub-optimal structure (Hervé et al., 2015). These two studies that primed ungrammatical or discourse-pragmatically sub-optimal structures are particularly relevant to the issue of cross-linguistic influence.

In an independent line of research, recent work on the priming of ungrammatical structures in monolingual adult speakers offers some insight into how ungrammatical production would arise in the context of cross-linguistic influence in bilinguals. In a series of four syntactic priming experiments Ivanova, Pickering, McLean, Costa, and Branigan (2012) tested whether English speakers could be primed to produce ungrammatical Double Object constructions with verbs that do not alternate between the Double Object and the Prepositional Object construction (e.g. *The dancer donates the soldier the apple). The only condition in which speakers could be successfully primed to produce ungrammatical Double Object constructions with non-alternating verbs was when there was lexical overlap of the non-alternating verb (e.g. donate) between the prime, and the target. Neither grammatically well-formed primes (e.g. The nun gave the monk the book), nor ungrammatical primes containing a different non-alternating verb (e.g. Prime: The policeman returned the dancer the banana; 
Target: donate) increased the likelihood of producing an ungrammatical nonalternating verb in the target. The lack of priming in the absence of lexical overlap led the authors to argue against a non-lexicalist view where syntactic structure per se can be primed. Instead, Ivanova et al. (2012) interpreted these results as consistent with a lexicalist approach where priming is the result of the increased activation of a syntactic structure that is in turn mediated by the activation of the lemma node associated with the verb in the construction. The persistence of other types of grammatical violations (e.g. island constraint violations such as * What does Alex like the woman who wears?) might be more likely to depend on abstract structural mechanisms as the specific lexical content of the sentence does not determine its ungrammaticality.

Models of structural priming have so far been particularly focused on the nature of syntactic structures that involve an important lexical component tied to the verb, i.e., the Double Object/Prepositional Object dative alternation, the active/passive alternation. The activation of the relevant syntactic structures in these cases - and their subsequent availability for production - is predicated upon the activation of the verb lemma (e.g. give) and the combinatorial nodes it is associated with (i.e. the NP, NP node for the DO construction or the NP, PP node for the PO construction). While this conceptualization of syntax works well in the case of argument structure and argument linearization when there is an explicit verb lemma component, it is less clear how phenomena such as whmovement or subject omission, where such a strong lexical component is absent, would be amenable to the same treatment. This is where a model of syntactic representation like the LSM can make an explicit contribution. 
The LSM offers a way to combine the idea of primed ungrammaticality with the notion of cross-linguistic influence of abstract syntax. The basic tenet of the LSM (Lillo-Martin et al, 14) is that bilingual speakers have two sets of Lists corresponding to the different stages of the syntactic derivation and that bilinguals may freely draw from either set at any point in the derivation. Instances of cross-linguistic influence in Language a thus arise when bilinguals produce structures that include Vocabulary Items from Language a but where the syntactic operations that take place before Spell Out operate on abstract syntactic features that come from Language $\alpha$. Working at the level of abstract syntactic features and syntactic operations circumvents the problem of limiting the study of cross-linguistic priming to the level of structures that have a stronger lexical component and extends it, in principle, to any syntactic phenomenon. For instance, sub-optimal overt subject pronouns in a null-subject language would arise when the Vocabulary Items, i.e. pronouns, are drawn from Language a, but the selection of the syntactic operations that apply to the derivation are drawn from Language $\alpha$ (the non-null subject language). Unlike in null-subject languages like Italian, where the Extended Projection Principle - EPP - is checked by a D-feature on the verb through head movement, in non-nullsubject languages like English the EPP is satisfied by an overt DP. The possibility of drawing on the syntax of English while using Italian would account for the (over)use of overt pronouns by Italian-English bilinguals.

At the same time, the idea of activation from the priming literature provides the LSM with a rationale for what would trigger the selection of the non-target language before Spell Out, something that is not specified in this representational model. The prediction is therefore that the likelihood of 
ungrammatical or sub-optimal structures in Language a - arising from the selection of syntactic operations from Language $\alpha$ - are going to be more likely to occur if the activation stage of Language $\alpha$ is high due to recent use.

\section{Word count:}

Author's address

Ludovica Serratrice

School of Psychology \& Clinical Language Sciences

University of Reading

Harry Pitt Building

Earley Gate

Reading RG6 7BE

UK

Email: Serratrice@manchester.ac.uk

\section{References}

Amaral, L., \& Roeper, T. (2014). Multiple grammars and second language representation. Second Language Research, 30(1), 3-36.

Bernolet, S., Hartsuiker, R. J., \& Pickering, M. J. (2007). Shared syntactic representations in bilinguals: Evidence for the role of word-order repetition. Journal of Experimental Psychology: Learning, Memory, and Cognition, 33(5), 931-949.

Bock, J. K. (1986). Syntactic persistence in language production. Cognitive Psychology, 18(3), 355-387. 
Branigan, H. P., \& McLean, J. F. (2016). What children learn from adults' utterances: An ephemeral lexical boost and persistent syntactic priming in adult-child dialogue. Journal of Memory and Language. doi:10.1016/j.jml.2016.02.002.

Chang, F., Dell, G. S., \& Bock, K. (2006). Becoming syntactic. Psychological Review, 113(2), 234-272.

De Houwer, A. (1990). The acquisition of two languages from birth: A case study. Cambridge University Press.

den Dikken, M. (2011). The distributed morphology of code-switching. UIC Bilingualism Forum, University of Illinois.

Desmet, T., \& Declercq, M. (2006). Cross-linguistic priming of syntactic hierarchical configuration information. Journal of Memory and Language, 54(4), 610-632.

Genesee, F. (1989). Early bilingual development: one language or two?. Journal of Child Language, 16(1), 161-179.

Halle, M., \& Marantz, A. (1993). Distributed morphology and the pieces of inflection. In K. Emmorey \& H. Lane (Eds.), The view from building 20: Essays in honour of Sylvain Bromberger (pp. 111-176). Cambridge: Cambridge University Press.

Hartsuiker, R. J., Pickering, M. J., \& Veltkamp, E. (2004). Is syntax separate or shared between languages? Cross-linguistic syntactic priming in SpanishEnglish bilinguals. Psychological Science, 15(6), 409-414.

Hartsuiker, R., \& Pickering, M. (2008). Language integration in bilingual sentence production." Acta Psychologica, 128(3), 479-489. 
Hartsuiker, R. J., Beerts, S., Loncke, M., Desmet, T., \& Bernolet, S. (2016). Crosslinguistic structural priming in multilinguals: Further evidence for shared syntax. Journal of Memory and Language, 90, 14-30.

Hervé, C., Serratrice, L., \& Corley, M. (2015). Dislocations in French-English bilingual children: An elicitation study. Bilingualism: Language and Cognition, available on CJO2015. doi:10.1017/S1366728915000401.

Hsin, L., Legendre, G., \& Omaki, A. (2013). Priming cross-linguistic interference in Spanish-English bilingual children. In Proceedings of the 37th Annual Boston University Conference on Language Development (pp. 165-77). Somerville, MA: Cascadilla Press.

Hulk, A., \& Müller, N. (2000). Bilingual first language acquisition at the interface between syntax and pragmatics. Bilingualism: Language and Cognition, 3(3), 227-244.

Ivanova, I., Pickering, M. J., McLean, J. F., Costa, A., \& Branigan, H. P. (2012). How do people produce ungrammatical utterances?. Journal of Memory and Language, 67(3), 355-370.

Kantola, L., \& van Gompel, R. P. (2011). Between-and within-language priming is the same: Evidence for shared bilingual syntactic representations. Memory \& Cognition, 39(2), 276-290.

Loebell, H., \& Bock, K. (2003). Structural priming across languages.

Linguistics, 41(5), 791-824.

MacSwan, J. (2000). The architecture of the bilingual language faculty: Evidence from intrasentential code switching. Bilingualism: Language and Cognition, 3(1), 37-54. 
MacSwan, J. (2005). Codeswitching and generative grammar: A critique of the MLF model and some remarks on "modified minimalism". Bilingualism: Language and Cognition, 8(1), 1-22.

MacSwan, J. (2014). Programs and proposals in codeswitching research: unconstraining theories of bilingual language mixing. In J. MacSwan (Ed.), Grammatical theory and bilingual codeswitching (pp. 1-33). Cambridge, MA: The MIT Press.

Meisel, J. M. (1989). Early differentiation of languages in bilingual children. In Hyltenstam, K., \& Obler, L. K. (Eds.), Bilingualism across the lifespan: Aspects of acquisition, maturity and loss (pp. 13-40). Cambridge: Cambridge University Press.

Paradis, J., \& Navarro, S. (2003). Subject realization and crosslinguistic interference in the bilingual acquisition of Spanish and English: what is the role of the input?. Journal of Child Language, 30(2), 371-393.

Pickering, M. J., \& Branigan, H. P. (1998). The representation of verbs: Evidence from syntactic priming in language production. Journal of Memory and Language, 39(4), 633-651.

Serratrice, L., Sorace, A., \& Paoli, S. (2004). Crosslinguistic influence at the syntax-pragmatics interface: Subjects and objects in English-Italian bilingual and monolingual acquisition. Bilingualism: Language and Cognition, $7(3), 183-205$.

Vasilyeva, M., Waterfall, H., Gámez, P. B., Gómez, L. E., Bowers, E., \& Shimpi, P. (2010). Cross-linguistic syntactic priming in bilingual children. Journal of Child Language, 37(5), 1047-1064. 
Volterra, V., \& Taeschner, T. (1978). The acquisition and development of language by bilingual children. Journal of Child Language, 5(2), 311-326.

Wolleb, A. (2015). Syntactic representations in the bilingual mind: the role of executive function and pragmatics in cross-language priming. Unpublished PhD dissertation, University of Trømso. 